Journal of Research in Interprofessional

Practice and

Education

Vol. 9.1

2019

\title{
Interprofessional Learning in the Simulation Laboratory: Nursing and Pharmacy Students' Experiences
}

\author{
Hege Hammer ${ }^{\mathrm{a}}$, MD, ANP; \\ Frøydis Perny Vasset ${ }^{\mathrm{b}}$, PhD
}

\begin{abstract}
Background: Using simulation as an educational method to learn collaborative practice requires the involvement of various professional education programs where the intention is to learn from, with, and about each other.

Methods: This study describes pharmacy and nursing students' experiences with interprofessional education. After interprofessional simulation, three focus group interviews with bachelor students were conducted. The data were analysed using Giorgi's qualitative content analysis method.

Findings: The students found that IPE closed knowledge gaps, change a stereotypical perception of professional roles, and enhance patient safety. Full-scale simulation appears to be an effective arena for learning clinical judgement, improving communication skills, and developing knowledge of pharmacodynamics.

Conclusion: Interprofessional education may be necessary for professionals to enhance their ability to interact more effectively in the future.

Keywords Nursing students; Pharmacy students; Collaboration; IPE; Patient safety
\end{abstract}

\section{Introduction}

\section{Interprofessional collaborative training for nursing and} pharmacy students

The World Health Organization (WHO) [1] urged health education institutions

Journal of Research in Interprofessional Practice and Education (JRIPE)

Vol. 9.1

(C) 2019

doi: 10.22230/jipe.2019 v9n1a277

Corresponding author: Hege Hammer. Email: hege.hammer@nord.no. around the world to train students to become comfortable with future interprofessional interaction. The Ministry of Education [2] launched the concept of interprofessional learning (IPL) as a learning platform through which students from different professional education programs learn together and gain insight into the skills of others. Interprofessional learning occurs when two or more professions learn, interact, and teach each other to improve the quality of service and to stay-upto-date to provide better services to patients [3]. All health services are under pressure with increasing demands for efficiency. The Ministry of Health and Care [4] indicates increasing demands for different health services and outlines that services cannot meet these demands simply by providing additional financial resources. 
2

Interprofessional Learning in the Simulation Laboratory

Hammer \& Vasset

Journal of Research in Interprofessional Practice and Education

Vol. 9.1

2019
Those involved must find new ways of distributing tasks and find new solutions in the workplace to ensure high-quality and productive services. The emphasis is on what happens between different actors, management levels, and services and, not least, between professionals and users [4].

Knowledge is viewed as designed and appropriated through social interaction, involvement, collaboration, and active participation and as a cognitive and mental capacity [5]. Professional knowledge is one of the support pillars of a profession, and various professionals can perceive interprofessional collaboration as a threat to the existence of their area of specialization and to the importance of their subject [6]. Lindgard et al. [7] emphasize that a lack of collaboration is a critical factor in failing to reach common objectives in the treatment of patients, and that the need for IPL has increased, mostly due to the increasingly complex disorders of patients. Collaboration across professions can thus be a useful way to meet the challenges [8]. It is expected that students will develop integrated professional competencies and will be able to meet changing needs and that further collaboration between professions will develop. To acquire interprofessional interaction competencies, students must have opportunities to practice IPL during their initial study time [2].

The aim of this study is to investigate the experience of nursing and pharmacy students during their interprofessional collaborations in the simulation laboratory. Pharmacists collaborate with nurses and other professions to coordinate and deliver medicines. In both hospitals and municipalities, pharmaceutical skills are increasingly needed in clinics [9]. Pharmaceutical competence promotes patient safety and can further develop interprofessional competence and sustainable professional environments [10]. Interprofessional collaboration among pharmacists, nurses, and doctors to ensure a clinical focus and the proper use of medicines is an important factor in ensuring and improving health services for everyone [9].

\section{Simulation as an educational method for student learning}

For bachelor's degree students to be equipped for their practice studies, there has been a tradition of practical training of procedures in the practice department of the nursing program. To improve this approach, a simulation centre is set up with simulators. Simulation is used to imitate a real situation using a model of the environment. Using a simulator can encourage the application of simple skills and allow more complex interpersonal relationships to be encountered [11]. A facilitator will typically lead the planning and implementation of the simulation [12]. The purpose of this study is to investigate pharmacy and nursing students' experiences with IPL and the use of simulation as an educational aid.

Earlier studies [13-16] refer to some common factors regarding simulation as an educational aid. Simulation can be conducted in the field of practice or through school-based education [17]. Clinical skills and student interprofessional collaboration may be limited for students, and the use of IPL in education can thus be useful [18]. Interprofessional learning must be implemented at the management level, because it can require resources and a strategic effort to establish it in educational programs and the working environment $[19,20]$. 
3

Interprofessional Learning in the Simulation Laboratory

Hammer \& Vasset

Journal of Research in Interprofessional Practice and Education

Vol. 9.1

2019
Simulation allows participants to reflect critically on the activity in the scenario and imitate reality [12]. Research emphasizes that pedagogical methods that increase student activity and realistic situations in teaching provide better learning. The use of simulation as a learning activity has proven suitable for reducing the gap between theory and practice because it creates a realistic learning environment with reality-related situations. Such training can also greatly increase patient safety after practitioners graduate and start practicing [21-23]. In this study, medicine handling was an important safety aspect. The WHO [24] emphasizes that students need training in how to evaluate, prioritize, and respond on a knowledge-based basis so that patient safety is not threatened. The WHO recommends simulation training as an educational method to increase patient safety. Research underlines an increasing need for development and training in the use of simulated IPL tools and technological methods for collaboration. In simulation, training may be required on technological and facilitative aspects [12]. Students have noted that the summary debriefing after the simulation is an important part of the learning process [13]. Dieckmann et al. [13] also argue that reflecting on the work provides learning.

The literature of various professions emphasizes that if different professions collaborate, they can learn about each other and prevent negative stereotypes that can inhibit IPL [26-28]. Group-based collaboration across professions in the education sector can, therefore, contribute to better attitudes toward other professions. Interprofessional learning is characterized by shared objectives, mutual dependence, equal relationships between participants, and joint decisions and decision-making processes [6]. Vasset et al. [29] point out that while logistics, geography, and different organizational attachments can hinder IPL, interprofessional educational training using simulated patient cases can be easier to organize. Earlier research shows that students discuss realistic cases and then create a plan for examination and treatment based on common reflections [30].

The WHO [24] is a major contributor to implementing improved patient safety and the organization emphasizes knowledge seeking in the field. Students must be encouraged to ask difficult questions, for example, about what they do not understand, and share these questions with other students. This not only improves their own learning but also improves overall patient safety. Several researchers support the claim that IPL can improve patient safety [21-23,36]. Emanuel et al. [30], for example, state that simulated cases have a useful role in learning about patient safety. Their study examined a case in which the learning outcomes were relevant also to both professions in this study. Medicines and clinical assessments are knowledge areas where the two professions possess different skills, but share a common objective: for the patient to be well and become healthier. Jeffries and Rogers [12] emphasize that learning outcomes must be clear and match the knowledge and experience of those who learn. Karina Aase [21] writes that common learning objectives must be developed to achieve the purpose of IPL simulation, as well as course descriptions. Interprofessional learning can be a complex and problematic process and is, therefore, characterized by semantic (theoretical) and syntactic (contextual, linguistic) knowledge barriers [31]. Guidance in the simulation context, where sev- 
4

Interprofessional Learning in the Simulation Laboratory

Hammer \& Vasset

Journal of Research in Interprofessional Practice and Education eral professions collaborate, depends more on processes and less on subjects. The facilitator role is important in simulations [12]. This professional manages or guides the different parts of the simulation. The role may involve defining learning outcomes, introducing the simulation, setting rules for it, and participating in implementing the simulation and leading the debriefing [12]. Time pressure, which is often a major challenge in all health and social work, is also a challenge for simulation-based learning $[13,20]$. To meet the need described in national management documents requiring IPL, improved health-care and patient safety require further study and opportunities to improve the knowledge and competence levels of health students.

The patient case: Lessons to be learned

Students (nursing and pharmacy) collaborated in a simulation laboratory with a "patient" in need of relief, palliative intervention, due to cancer with metastasis, and a treatment regimen (chemotherapy). Two pharmacy students and two nursing students acted in each simulation intervention, and one nursing student and one pharmacy student had observer status. Each simulation team had six students. In total, 60 students participated. At the end of each simulation intervention, the students debriefed with the facilitator (a nursing teacher) and one pharmacy teacher. In all, this pedagogical intervention took one hour.

Both nursing and pharmacy students emphasize clinical observations using the ABCDE (Airway, Breathing, Circulation, Disability, Exposure) methodology in the simulations situations. The effects of measures, drugs, patient communication, and interprofessional collaboration were fundamental. A high-technology advanced SimMan $3 \mathrm{G}$ patient simulator with automatic drug recognition was used in the simulation. The environment was organized to make it appear as if the patient was real.

In the debriefing situations, the nursing and pharmacy teachers conducted the reflection interviews with the entire group. Debriefing has three stages: description phase, analysis phase, and application phase [39].

Simulation is intended to imitate a real situation in which you create a model of the environment, the available resources, and the people involved. Simulation as a method allows participants to critically reflect on realistic situations and each other's activity in the scenario [12]. A simulation can largely re-create reality, or it can mimic multiple aspects of a situation in combination to achieve learning goals [21]. The use of simulation as a learning activity has proven to be suitable for reducing the gap between theory and practice because it creates a realistic learning environment with lifelike situations [42].

The research question for this study was: what are the experiences of pharmacy and nursing students in simulations as an educational method to promote interprofessional collaborative skills?

\section{Method}

A qualitative descriptive methodology was used to emphasize the understanding of the social phenomena [32]. Focus group interviews used a phenomenologicalhermeneutical approach [32]. This tradition is based on theories of interpretation 
5

Interprofessional Learning in the Simulation Laboratory

Hammer \& Vasset
Journal of Research in Interprofessional Practice and Education

Vol. 9.1

2019 (hermeneutics) and human experience (phenomenology). The goal is to explore how the parties involved understand the phenomena [33].

\section{Sample}

This study included students in their second year of pharmacy and nursing programs (see Figure 1). According to Tove Thagaard [34], this type of strategic selection is essential when selecting respondents based on the characteristics and qualifications relevant to the research question. The first step was to recruit participants for the interview. All students were invited to participate in an interview, and 16 of them accepted; therefore, 27 percent of the students participated in the focus groups. Students were divided into three focus groups, with eight from each profession. Gender and age did not become important factors in this study.
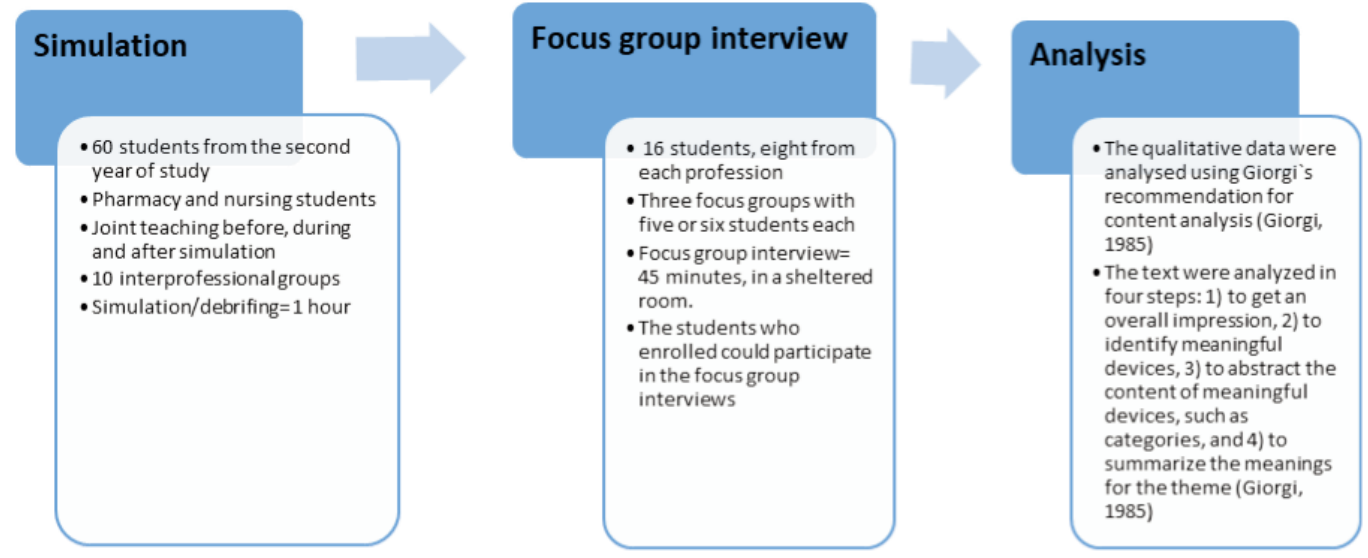

Figure 1. The process, from simulation to analysis, of the IPL project

\section{Data collection}

This study used a semi-structured interview guide with three parts, each with its own theme, with additional supplementary questions and discussion points [32]. Focus group interviews is a useful method for exploring students' experiences because the researcher can sense whether there is any interaction between the members of the focus group [32]. The interviews were recorded on a Dictaphone, and transcribed verbally. The recording was deleted after transcription. The moderator conducted the interviews and had an assistant list the important elements that appeared in the discussions.

\section{Main interview topics}

Reflection questions:

1 How did you experience interprofessional collaboration in the simulation situation?

2 How do you present and advocate for your knowledge and roles in collaboration with other professionals?

3 What did you learn about the other professionals' roles in their work?

4 Can you try to describe the benefits and disadvantages of this educational approach? 
Interprofessional Learning in the Simulation Laboratory

Hammer \& Vasset

\section{Journal of Research in Interprofessional Practice and Education}

Follow-up questions:

1 Which aspect of your action skills do you think was improved with IPL?

2 Which aspect of your knowledge expertise do you think was improved with IPL?

3 How do you think that interprofessional simulation training can contribute to patient safety?

Summary questions:

1 Would it be useful to perform a similar IPL arrangement later in the course?

2 If so, would you propose implementing this arrangement?

The content was abstracted into two main themes: students' experiences with IPL in the simulation laboratory and students' experiences of interprofessional education and supervision. The data collection was completed in 2017.

\section{Analysis}

The analysis followed Amedeo Giorgi's [35] recommendation for content analysis by condensing the responses into meaningful statements and categorizing them. Then, thematically based on the main topics in the interviews, the following steps were taken:

1 The text was read to obtain an overall impression of the respondents' experiences.

2 The transcripts were read in detail to identify meaningful topics.

3 The content of the meaningful themes was abstracted and coded.

4 The essence of each of the code groups was summarized and used to develop categories, which formed the basis of the results section.

\section{Ethical considerations}

The study is bound by the rules of the Norwegian Centre for Research Data (NSD). The NSD accepted the study and provided it with the number 50533. A request to conduct the project was sent to the faculty of the associated university and NSD. The students who agreed to participate in the study were given the opportunity to withdraw from the focus group interview without giving a reason. The respondents were guaranteed anonymity, and the audio recordings were deleted after transcription. Both the transcribed data and the audio recordings were stored on a secure device on a computer.

\section{Results}

The students' experiences were abstracted into two meaningful topics:

1 Nursing and pharmacy students' experiences with IPL.

2 Nursing and pharmacy students' experiences of interprofessional training in a simulator laboratory.

Both main themes are coded with three subcategories, and direct quotes from the respondents are provided in italics. Both the first and second authors coded the data. 
7

Interprofessional Learning in the Simulation Laboratory

Hammer \& Vasset

Journal of Research in Interprofessional Practice and Education Vol. 9.1 2019

\section{Theme 1: Nursing and pharmacist students discover the expertise of the other profession}

Learn from, with, and about each other

The pharmacy students stated that the nurses worked hard to help the patient who lay in bed, but they themselves had only a small role in the case. Some of the respondents said the two groups possess two very different basic sets of knowledge. One nurse who stated that the two courses were very different said: Something was completely - "Greek"-for us. Another nursing student said: The distinction is clear that there was not much collaboration. During the simulation itself, the nurses had their defined tasks, and the pharmacy students found that they were standing on the sidelines playing a somewhat inactive observer role. A pharmacy student said that we communicate with the patient as a customer and not as a patient. They also found that the communication differences contributed to different treatment considerations. One of the respondents said, this shows how differently we think because when we talked about depression, you thought she should get antidepressants, while we think that, no, we should also talk to the patient. All the respondents said they had much to learn from each other. I have gained insight that it is important to use the pharmacist for what they can do and that we learn from them and use them in other situations than just to add medicine, said one nursing student.

\section{Experiences with professional collaboration regarding patient safety}

The nursing students were keen to initiate the clinical eye and take the signs faster. The ethical aspects were described as positive, as they learned to reflect in a different way. One of the pharmacy students emphasized that it became apparent that the nurses can do a lot more things than we can! Nursing students stated that they themselves had a broad but not always profound competence. They said that their clinical action skills improved with each simulation session, while the pharmacy students said they lacked simulation in their education. One of them said, I can't associate this with a drugstore, but I have learned how it is practically used in hospitals. All the respondents pointed out that interprofessional simulation training led to increased understanding and awareness of the competence of the other profession. The students also said that this type of IPL could lead to increased patient safety: Simulation initiates the thought process and prepares us for the real world of work. Several respondents pointed out the positive aspects of being able to fail without compromising the patient's health.

\section{Challenges in the IPL situation}

Some of the pharmacy respondents said that the pharmacy students should have more complementary roles and responsibilities in the simulation arrangement. A pharmacy student said: We have to dare to challenge ourselves more in the simulation itself to demand a broader collaboration between nurses and pharmacists. Many of the respondents said they could imagine a scenario in which pharmacy students had to suggest medications for symptom relief. They reported that they could all benefit from a simulation follow-up. Perhaps a scheme that is conducted over two different 
8

Interprofessional Learning in the Simulation Laboratory

Hammer \& Vasset

Journal of Research in Interprofessional Practice and Education

Vol. 9.1

2019 weeks with different themes will better combine the subjects, one of the respondents said. To take advantage of the SimMan's full potential, a pharmacy student expressed a desire to give the doll medications and to observe what's happening, see the wrong development, with the wrong preparations. All the respondents also emphasized that they felt time pressure during the work of the simulation laboratory.

\section{Theme 2: Nursing and pharmacy students agreed that the reflection and debriefing were useful in the simulator laboratory}

\section{Preparation for simulation in IPL}

Some respondents stated that they had enough information about IPL in advance, but some said the opposite. This lack of information led to uncertainty in relation to the simulation.

The pharmacy students said that simulation was new to them. The nursing students stressed that the pharmacy education portion of the common introductory day was a new and difficult subject for them. One nursing student said: They were two steps ahead of where we were, and maybe more than that. The pharmacy students expressed the benefit of a common introduction to the simulation.

Experience with guidance: Interprofessional tasks

The participants described the interprofessional simulation as a positive experience. They reported that they should have counselled toward the end of the project week and before the actual simulation presentation. A nursing student said: It was only at the end that we started to get an overview.

\section{Reflection and debriefing after the simulation}

The respondents stated that the debriefing was the most instructive part of the simulation because the learning outcomes of the IPL were central. It was definitely the most educational part, a respondent said. Another pharmacy student said: It was only in the debriefing when we began to talk about the adverse event of cytostatic that you see the full context. Nevertheless, some of the students felt that they should have had more time in the simulation situation itself. The respondents agreed that both professional levels of competence manifested themselves during the debriefing. Clinical reasoning and reflection about the patient situation were developed. One of the pharmacy students claimed to use a little extra oxygen when the patient is blue on his lips. Then, we learned how the scoop (patient monitor) works and why ABCDE is important. It's so obvious afterward!

\section{Discussion}

\section{Experiences with IPL in simulation situations}

The pharmacy students argued that it took time to acquire an overview regarding which tasks should be carried out and processed, and by whom. Useful and adequate information on the roles of the different professionals provided in advance, as well as guidance during the learning situation, can relieve the challenges of IPL $[16,22]$. Dieckmann et al. [13] show that respondents in their study did not receive enough information about the simulation as a whole and that facilitation should 
9

Interprofessional Learning in the Simulation Laboratory

Hammer \& Vasset

Journal of Research in Interprofessional Practice and Education

Vol. 9.1

2019 have been provided several times to achieve better learning outcomes, especially as the pharmacy students had not previously used the simulation method.

The respondents in this study claimed that insight into the work of the other professions was useful to them because they learned much about their specific competencies. The use of facilitation later in the process would provide them with a better opportunity to take advantage of the interprofessional complexity that arose. To form successful interprofessional collaborations, Aase et al. [16] state that role identities must be balanced. This finding is similar to the results of the study by Ottis and Gretchen [36]. Through this IPL study, interactions increased, and the students gained a better understanding of their clinical and social responsibilities. In addition, the students experienced better attitudes toward IPL and increased knowledge about the technology used, pursuant to Janet Willhaus [37]. The students said that they experienced strength in their professional identity by being challenged in their own field of study. This statement can be interpreted as indicating that interprofessional simulation can be useful for clinical practice as well as communication and collaboration competence.

When IPL is prioritized, it is often argued that an individual's professional knowledge is threatened [26-28]. A counterargument is that successful interactions will reduce prejudices. Increased contact with and knowledge of other professions, combined with respect, trust, and the understanding of one's own and others' professions, could change prejudices and stereotypes [26-28].

\section{Experiences with different communication traditions and knowledge skills}

Several pharmacy students concluded that one of the patients would benefit from antidepressants, while the nursing students preferred to treat the patient with conversation. It may appear that these students communicated very differently with each other and with the "patient." This difference may be a coincidence. Nevertheless, this bias manifested itself in different views of patient treatment, and it was explained by pharmacists' view of the patient as a potential customer. Semantic knowledge limits arise as a result of different interpretations, meanings, and opinions between the participants in an interprofessional collaboration [31]. Different communication patterns can create challenges, but the students recognized that this had to be overcome. Pharmacology is more based in the natural sciences, while the nursing program is characterized by a holistic view. This can explain the different ways of approaching the patient. It is natural for pharmacy student to emphasize different medications that may assist the patient. Pharmacists usually do not have long conversations with each and every customer in the drugstore. The customers come to the drugstore to obtain medications, not to receive conversation therapy.

Earlier research also indicates that improved communication skills are one of the success factors of IPL $[15,36,38]$. Participants may lose interest in the scenario if there are too many complex challenges or if little is relevant to their own functions and practical everyday life [13]. Some of the pharmacy students felt this way both because they knew that clinical skills, such as ABCDE observations, were not prioritized in their curriculum, and because they were unable to determine the relevance 
10

Interprofessional Learning in the Simulation Laboratory

Hammer \& Vasset

Journal of Research in Interprofessional Practice and Education

Vol. 9.1

2019 of these skills to their work in drugstores. Dieckmann et al. [13] emphasize that if the participants are willing to engage in the game as a simulated situation, it will be perceived as more relevant and realistic. This engagement will make the students more competent in simulations. In this study, it appears that the greatest challenge was that the pharmacy students had little experience with simulation laboratories. Consequently, the context was poorly understood, and their action repertoire was more limited than that of the nursing students. Nevertheless, the pharmacy students became fascinated during the experience and thought the knowledge was very useful. According to Paul Carlile [31], syntactic knowledge limits are created when processes within interprofessional collaboration are based on a professional language that only a few within the professional group understand. In this way, continuity in IPL will eventually create a common language across professional boundaries, thus contributing to eliminating the syntactic knowledge boundaries.

\section{Different roles and the usefulness of simulation and debriefing}

The results show that students in this study described the debriefing as the most crucial phase of the learning process. Several international studies also support this conclusion $[12,13,18]$. Respondents described the dialogue that takes place in the debriefings as structured, informative, clear, innovative, and informative. New et al. [38] stated that the participants' reflections strengthened a common understanding and learning. An argument in favour of reflecting in a debriefing and sharing one's experiences with others is that it will contribute to an individual student's development and learning. According to a selection of other studies, debriefing is absolutely essential when using simulation as an educational tool $[21,22,39]$. In this study, knowledge was only manifested at the debriefing stage.

Other research emphasizes a facilitator's ability to conduct successful simulations as crucial to creating a strong learning environment $[13,39]$. The respondents reported that it was essential that the facilitator had sufficient clinical and medical knowledge to help the students or to provide the right answers or a solution to the case. Facilitators from both professions participated in the debriefing, which, according to the results, appears to have been a positive experience. This finding is comparable to the study by Randi Tosterud [39] on the roles of facilitators in reflections. It is the actual reflection in the debriefing [25] that is important for learning: being able to reflect on what happened, why it happened, and what could have been done differently. The facilitator helps with this process. Several of the students, for example, discovered that there were side effects of the medicine that affected the patient's condition. The respondents pointed out that reflecting with participants from the other profession provided greater insight into the knowledge of that profession. Similar conclusions are described in Prescott and Garside's [40] study. Interprofessional learning seems to help students learn both together and apart when they reflect on the scenarios in a debriefing. Simulation situations with apparently identical external frameworks will probably be interpreted and perceived differently from one participant to another. This situation can also be explained by the professional-specific capital that the different student groups hold. Benner et al. [41] explain that emo- 
11

Interprofessional Learning in the Simulation Laboratory

Hammer \& Vasset

Journal of Research in Interprofessional Practice and Education

Vol. 9.1

2019 tional ambivalence lies in the contradictory discomfort that new experiences provide. The newly acquired competence provides a unique opportunity for further growth. Although the nursing students expressed their desire to be more comfortable with simulation as a working method, they also recognized the uncertainties, albeit not as significantly as the pharmacy students. The paradoxical nature of simulation also appears in other studies in which participants are brought out of their comfort zone, stimulated, and confronted [40].

Time pressure was one of the main barriers to simulation-based learning in this study, and international studies report similar findings $[13,20]$. Time pressure is also a challenge in most health and social work and therefore something that students should learn to manage. The respondents pointed to a shortage of time, both in the debriefing and during the simulation, as one of the obstacles to successful IPL. The participants found that the pharmacy students were less active in the simulation process. A lack of experience with this teaching method could be a contributing factor. There must be sufficiently defined tasks for all the professions. Dieckmann et al. [13] mention that a well-organized simulation setup is one of the factors of success. A good work structure can be positive and decisive for the overall outcome. Interpro-fessional learning can be promoted by a joint professional curriculum and syllabus, and securing earmarked resources from management. Major inequalities in these areas provide weaker insights into the knowledge of the other profession and fewer benefits from IPL.

The pharmacy-related tasks were diffuse in this study, and the pharmacy students had little knowledge of the simulation department. The observer role could be perceived as less active in the simulation itself. Tosterud [39] claims that simulation in groups of two to ten students is preferable to avoid students becoming passive. Although this study had groups of five to six students, it did not engage everyone. Equality was seen as essential for establishing a truly interprofessional collaboration. Previous research indicates that students in the IPL context should have equal status and be in the same semester of their studies [26]. The observer role in this study was felt by some to be insufficiently active, but this cannot be generalized as a common impression because other respondents said the opposite. The respondents from the pharmacy study experienced the observer role as inactive. Their lack of simulation experience could be a contributing factor. Time pressure, non-matching simulation skills, and unclear expectations for the observer role can also be decisive factors. Several earlier studies [14,39] found that students seemed to benefit from having an observer role, where they had to contribute their findings mainly in the debriefing.

The students perceived that the learning outcomes related to patient safety would be relevant for both the nursing and pharmacy professions. Medicines and clinical assessments are knowledge areas in which the two professions possess different skills, but the common objective is that the patient should be well and become healthier.

Many of the respondents in this study said that they would benefit greatly from observing errors in medication in relation to changes in the vital parameters of the patient, for example, respiration, pulse, blood pressure, and pupil reaction to a given drug, such as an elevated opiate dose. The pharmacy students claimed that this might 
12

Interprofessional Learning in the Simulation Laboratory

Hammer \& Vasset

Journal of Research in Interprofessional Practice and Education

Vol. 9.1

2019 teach them to detect potential abusers in their customer base. It is important to note that these physiological parameters do not necessarily reflect opioid abuse; some of these signs will be seen in legitimate chronic-pain patients and/or in patients who experience accidental overdoses of pain medications.

A pharmacy student said that incorporating elements with errors in a simulation situation helped the participants remember the errors better so they would be able to transfer this experience to clinical practice. The WHO [24] recommendations indicate how to address incorrect treatment in practice, but here, failures during the simulation will not affect either syncope or relaxed respiratory drives. Reflecting on these aspects while being led by a trained clinician seems to increase patient safety $[25,30,39]$.

\section{Strengths and limitations}

This is a qualitative study; the findings cannot be generalized. The study provides results that may be interesting to pursue through further research, such as quantitative studies. The student focus groups contained both nursing and pharmacy students. This might make the students feel social pressure to not bring up negative impressions of the other profession and to possibly exaggerate their perception of the importance of collaboration between the two disciplines. One of the study's strengths is that there were two researchers throughout the process. It could also be considered advantageous that researchers from two different universities reviewed the results and that all students were invited to participate in the interviews. There were relatively few focus groups in the survey, but they answered the questions fairly equally.

\section{Conclusion}

The study shows that simulation-based IPL can be an educational method to teach students to collaborate across professions. The students perceived that the method contributes to increasing patient safety. They experienced bridge building between the two programs, nursing and pharmacy, which will help them eliminate negative perceptions of the other profession. They learned with, about, and from each other's knowledge. Different communication patterns provided new experiences, and the reflection in the debriefing provided new knowledge. The different levels of experience with simulation as an educational method created an obstacle to optimal interprofessional interaction.

This article emphasizes the following new local knowledge developed in a university in the central/western region of Norway:

- Different professions, such as pharmacy and nursing, have different approaches to patients; professionals in these fields also experience that they have different cultures and few commonalties.

- The simulation laboratory can be used to teach different professions how to collaborate.

- Learning to respect other professions and to understand each other's roles in the health system can enhance patient safety. 
Interprofessional Learning in the Simulation Laboratory

Hammer \& Vasset

Journal of Research in Interprofessional Practice and Education

Vol. 9.1

2019

\section{References}

1. World Health Organization. (2010). Framework for action on interprofessional education \& collaborative practice. Geneva, CH: World Health Organization.

2. Ministry of Education. (2011-2012). Utdanning for velferd. Samspill i praksis [Education for welfare. Interaction in practice]. White Paper, 13. Oslo, NO: Kunnskapsdepartementet.

3. Centre for Advancement in Interprofessional Education. (2002). Welcome to CAIPE. URL: http:/caipe.org.uk/about-us/defining-ipe/ [05.10,2017].

4. Ministry of Health and Care. (2008-2009). Interaction reform. White Paper, 47. Oslo, NO: Helse og omsorgsdepartment.

5. Newell, S., Robertso, M.,Scarbrough, H., \& Swan, J. (2009). Managing knowledge work and innovation. New York, NY: Palgrave Macmillan.

6. Lauvås, K., \& Lauvås, P. (2004). Tverrfaglig samarbeid - perspektiv og strategi [Interdisciplinary collaboration: Perspective and strategy]. Oslo, NO: Universitetsforlaget.

7. Lindgard, L., Espin, S., Evans, C., \& Hawryluck, L. (2004). The rules of the game: Interprofessional colaboration on the intensive care unit team. Critical Care, 8(6) 403-408.

8. Collin, K.M.,Valleala, U.M., Herranen, S., \& Paloniemi, S. (2012). Ways of interprofessional collaboration and learning in emergency work. Studies in Continuing Education, 34(3) 281-300.

9. Rosmo, K. (2016). Farmatid.no. URL: http://www.farmatid.no/artikler/nyheter/midtnorsk-storsatsing-pa-klinisk-farmasi [05.10,2017].

10. Helse-Midt-Norge (HMN). (2010). Strategi 2020. URL: https://ekstranett.helse-midt.no/1001 /Sakspapirer/sak\%2019-10\%20vedlegg\%20strategi\%202020\%20ver\%2009.pdf [05.10,2017].

11. Nelson, A. (2003). Using simulation to design and integrate technology for safer and more efficient practice environments. Nursing Outlook, 51, 27-29.

12. Jeffries, P.R., \& Rogers, K.J. (2012). Theoretical framework for simulation design. In P.R. Jeffries (Ed.), Simulation in nursing education from conceptualization to evaluation (pp. 25-41). New York, NY: National League for Nursing.

13. Dieckmann, P., Friis, S.M., Lippert, A., \& Østergaard, D. (2012). Goals, success factors and barriers for simulation-based learning. A qualitative interview study in health care. Simulation \& Gaming, 43(5), 627-647.

14. Efstathiou, N., \& Walker, W. (2014). Interprofessional, simulation-based training in end of life care. Journal of Interprofessional Care, 28(1), 68-70.

15. Bolesta, S., Pharm, D., \& Chmil, J.V. (2014). Interprofessional education among student health professionals using. American Journal of Pharmaceutical Education, 78(5), 1-9.

16. Aase, I., Hansen, B.S., \& Dieckmann, P. (2013). Teaching interprofessional teamwork in medical and nursing education in Norway: A content analysis. Journal of Interprofessional Care, 27(3), 238-245.

17. Vasset, F., \& Almås, S.H. (2015). Shadowing. Interprofessional learning. Journal of Research in Interprofessional Practice and Education, 5(2), 1-13.

18. Reeves, S., Perrier, L., Goldman., Freeth, D., \& Zwarenstein, M. (2013). Interproffesional education: Effects on interprofessional practice and healthcare outcomes. Cockrane Database of Systematic Reviews.

19. Bjørke, G., Almenning, T., Almås, SH., Brenna, S., Hansen, KK., Haugland, E., Luteberget, DL., Nesse, B., Nilsen, R., Nilsen, SR., Norengberg, DL., Røysing, H., \& Vasset, F. (2012). Kvalifisering for tverrprofesjonelt samarbeid i helse- og sosialsektoren [Qualification for crossprofessional cooperation in the health and social sector]. In Bjørke, G (ed) Sluttrapport - CABprosjektet [Collaboration across professional boundaries] (pp. 7-137). Oslo, NO: Høgskolen i Oslo og Akershus.

20. Cameron, A., Rennie, S., DiProspero, L., Langlois, S., Wagner, S., Potvin, M., \& Reeves, S. (2009). Re: An introduction to teamwork: Findings from an evaluation of an interprofessional education experience for 1000 first-year health science students. Allied Health, 38(4), 220-226.

21. Aase, K. (2010). Pasientsikkerhet - Teori og praksis i helsevesenet [Patient safety: Theory and practice in health care]. Oslo, NO: Universitetsforlaget.

22. Aase, I., Aase, K., Dieckmann, P., Bjørshol, C.A., \& Hansen B.S. (2016). Interprofessional communication in simulation-based training session in healthcare: A student perspective. Journal of Nursing Education and Practice, 6(7), 91-99.

23. Williams, B., \& Song, J. (2016). A simulated patient effective in facilitating development of clinical competence for healthcare students? A scoping review. Advances in Simulation, 1(6) 1-9.

24. World Health Organization. (2011). The WHO patient safety curriculum guide. URL: http://apps .who.int/iris/bitstream/10665/44641/1/9789241501958_eng.pdf [05.10,2017]. 
14

Interprofessional Learning in the Simulation Laboratory

Hammer \& Vasset
25. Nilsen, S.R., Røysing, H., \& Brynhildsen, S. (2002). Erfare, skrive, dele, diskutere og lære [Learn, write, share, discuss and learn]. Uniped, 35(2), 54-66.

26. Allport, G.H. (1954). The nature of prejudice. Boston, MA: M. Addison-Wesley.

27. Dickinson, C., \& Carpenter, J. (2005). Contact is not enough: An inter-group perspective on stereotype change in interprofessional education. In H. Colyer, M., Helme., \& I Jones (Eds). The Theory-Practice Relationship in Interprofessional Education. London: Higher Education Academy.

28. Barr, H., Koppel, I., Reeves, S., Hammick, M., \& Freeth, D.S. (2005). Effective interprofessional education: Argument assumption and evidence. Oxford, UK: Blackwell.

29. Vasset, F., Bergum, I., Inderhaug, H., \& Almås, S.H. (2014). Tverrprofesjonell e- læring som pedagogisk verktøy i helse- og sosialfagutdanninger [Interprofessional e-learning as an educational tool in health and social education]. Vård i Norden, 34(1), 19-23.

30. Emanuel, L., Berwick, D., Conway, J., Combes, J., Hatlie, M., Leape, L., \& Vincent, C. (2008). What exactly is patient safety? In K. Henriksen., J. Battles, M.A. Keyes, \& M.L. Grady (Eds). Advances in patient safety: New directions and alternative approaches. Rockville, MD. Agency for Healthcare Research and Quality.

31. Carlile, P. (2004). Transferring, translating, and transforming: An intergrative framework for managing knowledge across boundaries. Organization Science, 15(5) 555-568.

32. Malterud, K. (2017). Kvalitative forskningsmetoder for medisin og helsefag [Qualitative research methods for medicine and health care]. Oslo, NO: Universitetsforlaget.

33. Polit, D., \& Beck, C. (2017). Nursing research. Philedelphia, PA: Lippincott Williams \& Wilkins.

34. Thagaard, T. (2013). Systematisk innlevelse: en innføring i kvalitativ metode [Systematic empathy: An introduction to qualitative methodology]. Bergen, NO: Fagbokforlaget.

35. Giorgi, A. (1985). Sketch of a psychological phenomenological method. Phenomenology and psychological research: Essays. Pittsburg, PA: Duquesne University Press.

36. Ottis, E., \& Gretchen, G. (2016). An interprofessional nursing and pharmacy student simulation in acute pain management. Pharmacy Education, 16(1), 18-25.

37. Willhaus, J. (2012). Working toward interprofessional education with simulation. Nursing Education Perspectives. 33(2), 134.

38. New, S.N., Parham, J.S., Huff, D.C., Greenfield, T.L., Jennings, J.E., Schmidt, C.K., \& White, J.S. (2016). Interprofessional education: It's happening! Journal of Nursing Education and Practice, $6(9), 10-18$.

39. Tosterud, R. (2015). Simulation used as a learning approach in nursing education [Dissertation]. Sverige, SE: Karlstad University.

40. Prescott, S., \& Garside, J. (2009). An evaluation of simulated clinical practice for adult branch students. Nursing Standard, 23(22), 35-40.

41. Benner, P., Sutphen, M., Leonard, V., \& Day, L. (2010). A utdanne sykepleiere. Behov for radikale endringer [To educate nurses. Need for radical changes]. Oslo, NO: Akribe.

42. Weller, J.M. (2004). Simulation in undergraduate medical education: Bridging the gap between theory and practice. Medical Education, 38(1), 32-38.
Journal of Research in Interprofessional Practice and Education

Vol. 9.1

2019 